\title{
IMMUNOHISTOCHEMICAL LOCALIZATION OF TARTRATE RESISTANT ACID PHOSPHATASE (TRAP) IN DIVERSE ORAL TISSUES OF MICE AT DIFFERENT AGES
}

\author{
Amira E. Fares* and Iman M. Aboushady*
}

\begin{abstract}
Background: Tartrate-resistant acid phosphatase (TRAP) is considered to be a marker of the osteoclast and is also found to be critical for normal development of the skeleton.

Objectives: investigating the immunohistochemical distribution of TRAP in some oral tissues of mice at different age points.

Methods: Nine male mice from three different age groups (3 mice each) were used in the current study as follows: 1 day aged group, 1 week aged group and adult group. Animals of all groups were sacrificed and sections from skin side of lip, submandibular salivary gland, dorsal surface of tongue and enamel organ were prepared and subjected to histological and immunohistochemical examination to identify the differential expression of TRAP among these tissues.
\end{abstract}

Results: abundant immunohistochemical reaction to TRAP occurred in the granular convoluted tubules of the submandibular glands, in the hair follicles and sebaceous glands of the skin, in the surface layers of the dorsal surface of the tongue and among the different layers of the enamel organ. However, TRAP expression was more intense in the tissues of adult mice than that at earlier ages.

Conclusions: TRAP was intensely expressed in the oral tissues of adult mice rather than at earlier ages. These findings indicate that TRAP expression isn't restricted to osteoclasts, and thus, TRAP may be involved in biological processes other than bone remodeling.

KEYWORDS: TRAP, mice, submandibular glands, skin, tongue, enamel organ.

\section{INTRODUCTION}

Tartrate-resistant acid phosphatase (TRAP) is a binuclear iron-containing protein, capable of hydrolyzing a wide range of phosphate substrates including nucleotides, aryl phosphates and phosphoproteins including osteopontin and bone sialoprotein (Nash et al. 1993). Expression of TRAP is associated with the activation and differentiation of osteoclasts, as well as certain macrophages and other cells of monohistiocytic phenotype such as

* Lecturer, Oral Biology Department, Faculty of Oral and Dental Medicine, Cairo University 
the Gaucher cell (Robinson \& Glew, 1980 and Efstradiadis \& Moss, 1985).

TRAP has long been used as a histochemical marker for the osteoclast (Burstone, 1959). There is a direct relation between excessive osteoclast-facilitated bone resorption and the arrival of increased amounts of TRAP in the circulation. Therefore, serum TRAP has been indicated as a disease associated marker for the clinical diagnosis of excessive bone resorption and for quantitatively monitoring the rate and progression of metabolic bone disorders (Rico \& Villa, 1993). Activated human macrophages express the enzyme, particularly those of pulmonary alveolar origin (Efstradiadis \& Moss 1985). TRAP has also been identified in human placenta (Ketcham et al., 1989 \& Janckila et al., 1996), where the cell type expressing the enzyme is unclear, and similarly, it was observed in the odontoclasts resorbing enamel in human deciduous teeth before shedding (Sahara et al., 1998).

Furthermore, it is obvious from studies of its distribution that the enzyme is also expressed in other cells of macrophage lineage, and occasionally, in lymphoproliferative disorders. In the mouse, TRAP is expressed in many tissues in addition to bone, and the identification of the enzyme in murine dendritic cells suggests a function in T-cell immunity (Angel et al., 2000).

However, limited number of researchers has paid attention to the expression of TRAP in oral and dental tissues. Thus, this investigation was carried out to identify the normal expression of TRAP in some selected oral and dental tissues of mice, other than those of monocyte origin, at different ages.

\section{MATERIALS AND METHODS}

\section{Animals}

Nine male mice from three different age groups were used in the current study and they were divided as follows:
1 Day Aged Group: comprised 3 mice aged one day.

1 Week Aged Group: comprised 3 mice aged one week.

Adult Group: comprised 3 adult mice (aged about 3 months).

The mice were purchased from the animal house at the Faculty of Medicine, Cairo University. All procedures were conducted according to the recommendations of the ethics committee at the Faculty of Oral \& Dental Medicine, Cairo University.

\section{Sacrificing mice and Applied Investigations.}

Animals of all groups were sacrificed, by carbon dioxide inhalation. Then, for the first two groups, the whole head of each mouse was fixed in $10 \%$ neutral buffered formalin, dehydrated through graded alcohol, cleared in xylene and embedded in paraffin so that the heads were then cut in a sagittal plane. While for the third group, the adult lip, tongue, submandibular salivary glands and jaws were excised separately, and then fixed in $10 \%$ neutral buffered formalin. For soft tissue specimens, they are treated as previously mentioned, while for the excised jaws, decalcification was first performed through treatment with freshly prepared $14 \%$ neutral EDTA solution (Callis \& Sterchi, 1998) and then the ordinary preparation procedures were continued.

\section{Preparation of $14 \%$ neutral EDTA solution.}

140 Grams of free acid EDTA were added to $700 \mathrm{ml}$ distilled water. On a stir plate in the fume hood, ammonium hydroxide was added as $30 \mathrm{ml}$ at a time until the solution clears (about $90 \mathrm{ml}$ total). Water was then added to almost 1 liter. The $\mathrm{pH}$ was adjusted with ammonium hydroxide dropwise up to $\mathrm{pH} 7.2$, and then the final volume was adjusted to 1 liter. Afterwards, the previously fixed and rinsed jaw specimens were placed in at least 15 volumes of $14 \%$ EDTA which was changed daily for about 
two weeks. After decalcification, the jaws were then processed and embedded.

Sections of 4-6 $\mu$ thickness were prepared from the excised tissues and were subjected to the following investigations:

A. Histological Examination: using Hematoxylin and eosin stain.

B. Immunohistochemical Examination: The expression of tartrate-resistant acid phosphatase (TRAP) in the different mice specimens was studied among the selected ages.

\section{Immunohistochemical procedures}

Quenching endogenous peroxidase activity was performed by immersing the slides in 3\% hydrogen peroxide for $10 \mathrm{~min}$. Broad spectrum LAB-SA detection system from Invitrogen was used to visualize any antigen antibody reaction in the tissues. Background staining was blocked using $10 \%$ goat non immune serum blocker for $10 \mathrm{~min}$. Sections were then incubated with primary antibody against mouse TRAP (obtained from lab vision, USA). Henceforward, biotinylated secondary antibody was applied for $20 \mathrm{~min}$ followed by 20 min incubation with the enzyme conjugate. DAB chromogen was then applied for $2 \mathrm{~min}$, rinsed, after which counterstaining and cover slipping were performed. All slides were examined with light microscopy for histological evaluation and for detection of the specific brown reaction product of the DAB substrate in the immunostained sections.

\section{RESULTS}

\section{Submandibular Salivary glands}

Histological examination of the submandibular salivary gland of 1day-aged mice revealed a relatively small number of serous acini with narrow lumen $\&$ lined by high pyramidal cells. Excretory duct could be identified, but both striated duct and granular convoluted tubules were not yet developed.
The connective tissue septa were relatively wide (Fig.1-a). Regarding the immunohistochemical results of the mouse submandibular salivary gland at this age, a negative reaction to TRAP was observed (Fig. 1-b).

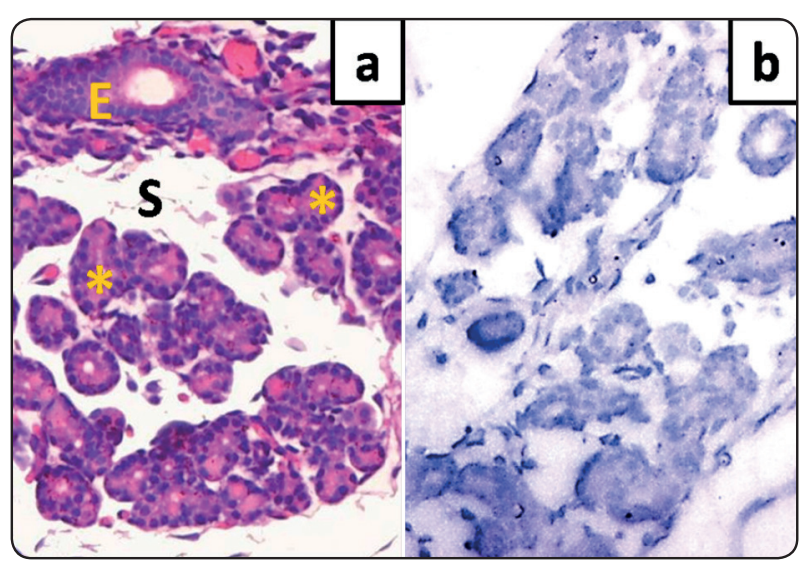

Fig. (1) Photomicrographs of the submandibular salivary gland of 1 day-aged mice showing: (a) Serous acini with narrow lumen \& lined by high pyramidal cells with basal rounded nuclei (stars), relatively wide connective tissue septa (s) and excretory duct (E) lined by pseudostratified columnar epithelium (H\&E $\mathrm{x} 400$ ). (b) Negative reaction to TRAP immunostaining (TRAP X 400).

The submandibular salivary gland of 1 weekaged mice revealed a larger number of serous acini as compared to those at one day age, the connective tissue septa was relatively thin, striated ducts have been developed at this age but still the granular convoluted tubules haven't yet developed (Fig. 2-a). As seen at one day age, the acini and ducts of one week aged-mice submandibular salivary gland revealed negative TRAP immunoexpression (Fig. 2-b).

On the contrary, the adult mice submandibular salivary gland showed a large number of well developed granular convoluted tubules containing apical eosinophilic granules (Fig. 3-a). Strong positive cytoplasmic TRAP immunostaining was clearly observed in the granular convoluted tubules of the adult submandibular salivary gland while the acini displayed a negative reaction (Fig. 3-b). 


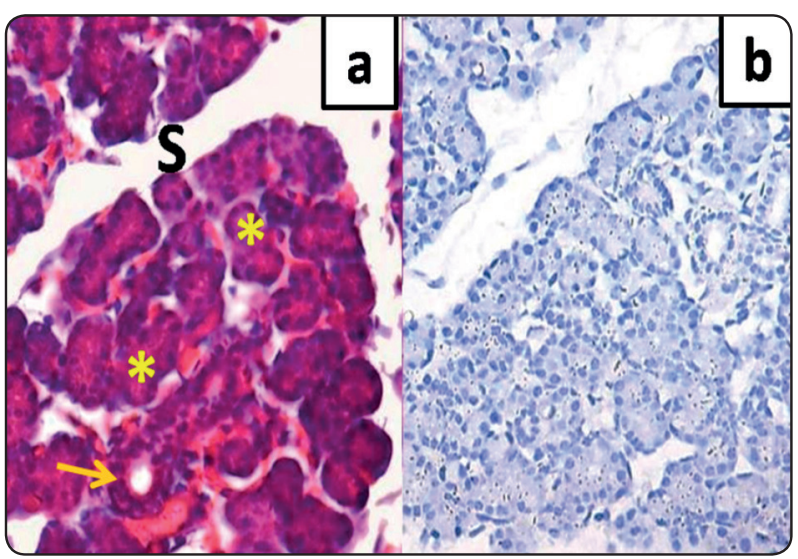

Fig. (2) Photomicrographs of the submandibular salivary gland of 1 week-aged mice showing: (a) Serous acini (stars), striated duct (arrow) and relatively thin connective tissue septa (s) (H\&E X 400). (b) Negative reaction to TRAP immunostaining (TRAP X 400).

\section{Skin side of the lip:}

The skin of one day-aged mice consisted of epidermis, dermis and skin appendages (hair follicles, sebaceous glands and sweat glands) (Figs. 4-a\&b). Moderate TRAP immunostaining was

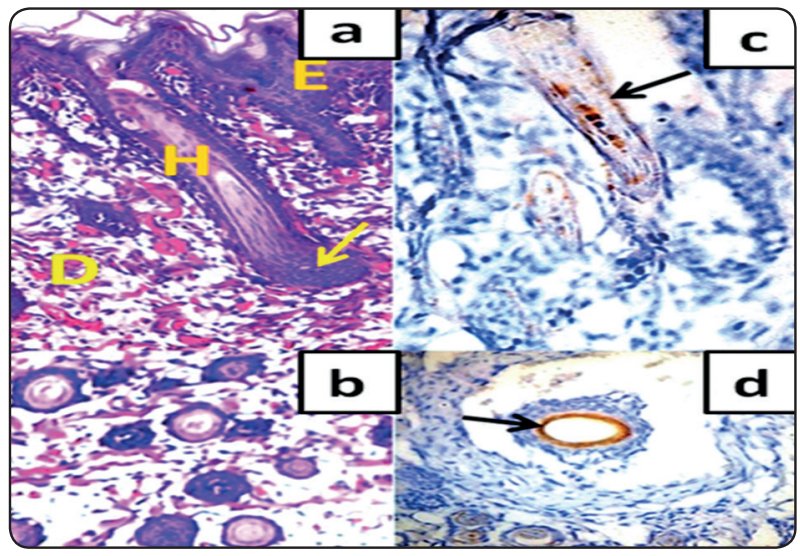

Fig. (4) Photomicrographs of the skin side of the lip of 1 dayaged mice showing: (a) Epidermis (E), dermis (D), hair follicle $(\mathrm{H})$ and sebaceous gland (arrow) (H\&E X 400) (b) T.S in hair follicles (H\&E X 400) (c) Moderately positive reaction to TRAP immunostaining in the hair follicle (arrow) (TRAP X 400) (d) T.S in hair follicle showing moderate TRAP immunostaining (arrow) (TRAP X 400)

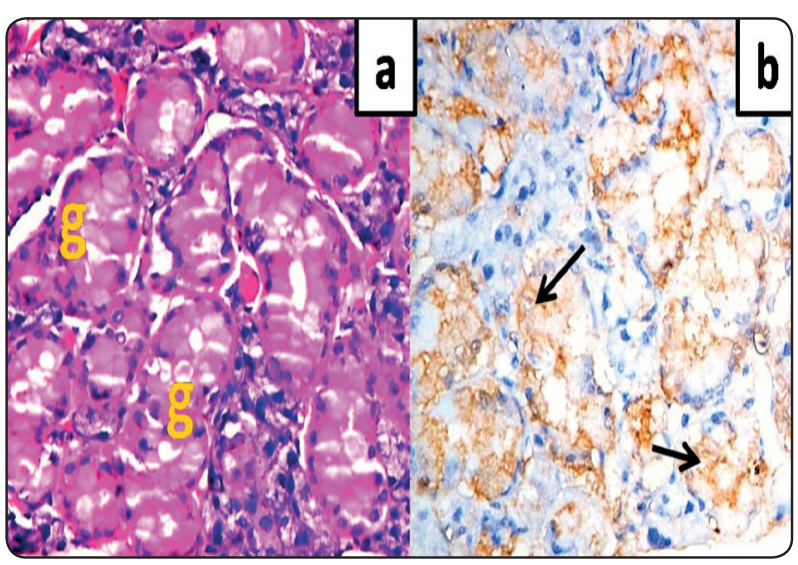

Fig. (3) Photomicrographs of the submandibular salivary gland of adult mice showing: (a) Well developed granular convoluted tubules (g) (H\&E X 400). (b) Strong cytoplasmicTRAP immunostaining among the granular convoluted tubule cells (arrows) (TRAP X 400).

observed in the hair follicles only (Figs. 4-c\&d). Similar observations were present in the skin of one week-aged mice (Figs. 5-a\&b). Whereas; the skin of adult mice exhibited stronger TRAP immunostaining in both the hair follicles and the associated sebaceous glands (Figs. 6-a\&b).

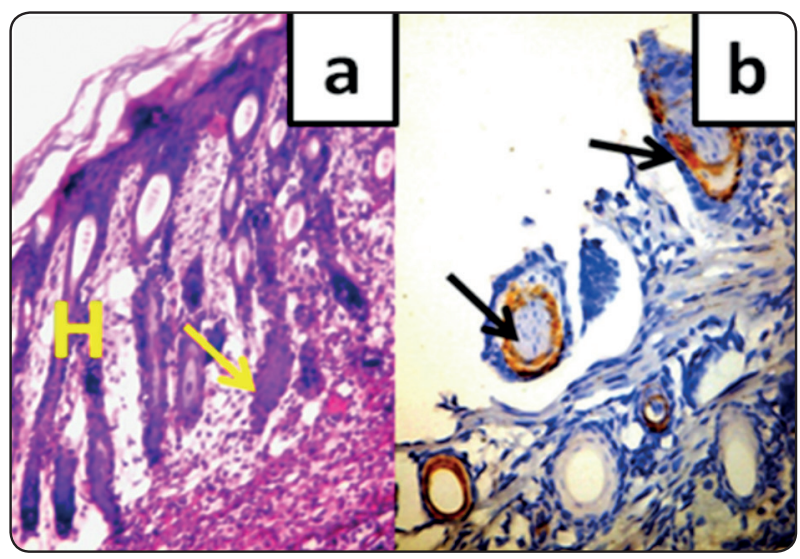

Fig. (5) Photomicrographs of the skin side of the lip of 1 weekaged mice showing: (a) Hair follicles (H) and sebaceous glands (arrow) (H\&E X 400) (b) Moderately positive reaction to TRAP immunostaining in the hair follicles (arrows) (TRAP X 400) 


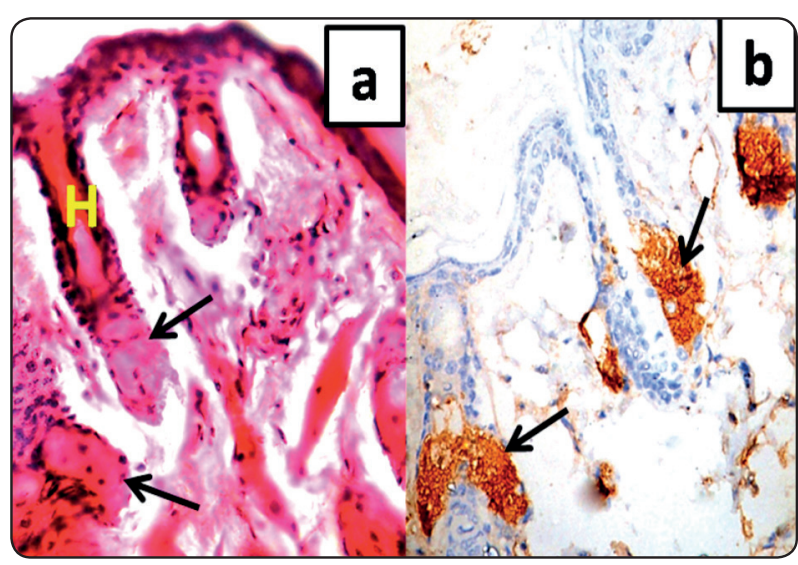

Fig. (6) Photomicrographs of the skin side of the lip of adult mice showing: (a) Hair follicles $(\mathrm{H})$ and sebaceous glands (arrows) (H\&E X 400) (b) Strong TRAP immunostaining in the hair follicles and sebaceous glands (arrows) (TRAP X 400)

\section{The dorsal surface of the tongue:}

The dorsal surface of the tongue of 1day aged mice was covered by relatively short filiform papillae (not completely developed) with a stratified squamous epithelial covering (Fig. 7-a). Negative TRAP immunostaining was obvious in the developing filiform papillae (Fig. 7-b). Well developed highly conical filform papillae was clearly seen in the dorsal surface of the tongue of 1 week aged mice having a keratinized stratified squamous epithelial covering (Fig. 8-a). Immunohistochemical evaluation of filiform papillae of the same age revealed a moderately positive TRAP immunostaining only in the granular cell layer of the stratified squamous epithelial covering (Fig. 8-b). The same observation was found in filiform papillae of adult mice where only the granular cell layer displayed a strongly positive TRAP immunostaining (Figs. 9-a\&b).

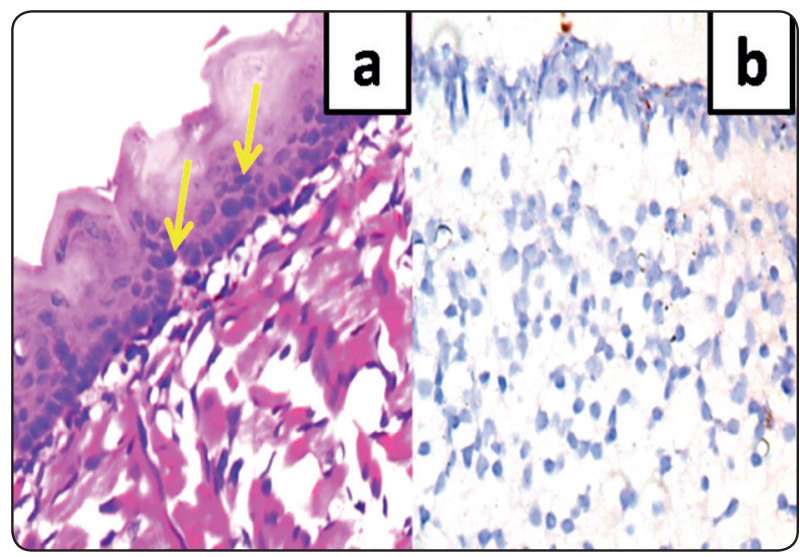

Fig. (7) Photomicrographs of the dorsal surface of the tongue of 1day aged mice showing: (a) Developing filiform papillae (arrows) (H\&E X 400) (b) Negative TRAP immunostaining in the developing filiform papillae (TRAP X 400)

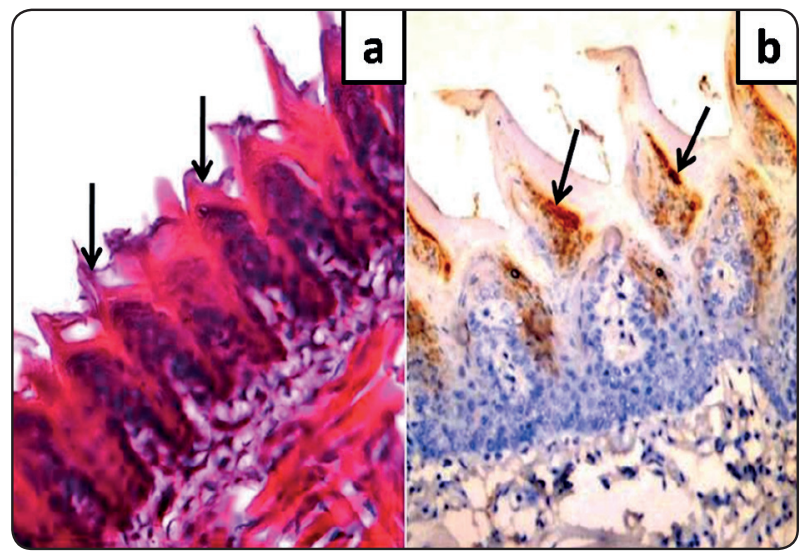

Fig. (8) Photomicrographs of the dorsal surface of the tongue of 1 week aged mice showing: (a) Well developed filiform papillae formed of keratinized stratified squamous epithelium (arrows) (H\&E X 400) (b) Moderate TRAP immunostaining in the granular cell layer of the epithelium covering the filiform papillae (arrows) (TRAP X 400) 


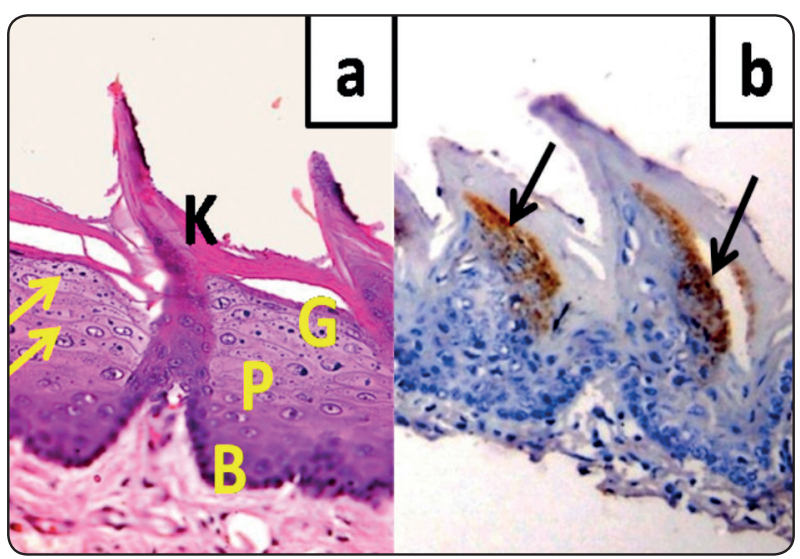

Fig. (9) Photomicrographs of the dorsal surface of the tongue of adult mice showing: (a) Well developed filiform papillae covered by keratinized stratified squamous epithelium formed of basal cell layer (B), prickle cell layer (P), granular cell layer (G) containing basophilic keratohyaline granules (arrows) and keratinous layer (K) (H\&E X 400) (b) Strongly positive reaction to TRAP immunostaining is well observed in the granular cell layer of the covering epithelium over the filiform papillae (arrows) (TRAP X 400)

\section{Enamel organs:}

Histological examination revealed that the late bell stage of tooth development was clearly observed in all the experimental groups with the following layers: ameloblasts, stratum intermedium, stellate reticulum \& outer enamel epithelim (Figs. 10, 11\&12-a). Although immunohistochemical examination revealed a negative reaction to TRAP in both 1day and 1 week aged mice (Figs. 10 \& 11-b); a strongly positive reaction to TRAP was clearly observed among the ameloblasts, stratum intermedium, stellate reticulum as well as in the blood vessels adjacent to the outer enamel epithelial cells of the enamel organs of adult mice (Fig. 12-b).

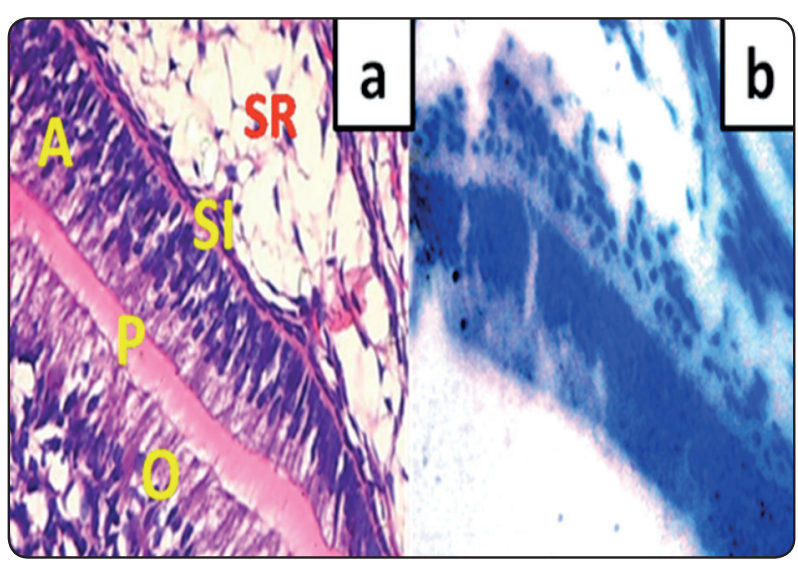

Fig. (10) Photomicrographs of the enamel organ at the late bell stage in 1 day aged mice showing: (a) Ameloblasts (A), stratum intermedium (SI), stellate reticulum (SR), predentin (P) and odontoblasts (O) (H\&E X 400) (b) Negative TRAP immunostaining in all layers of the enamel organ (TRAP X 400)

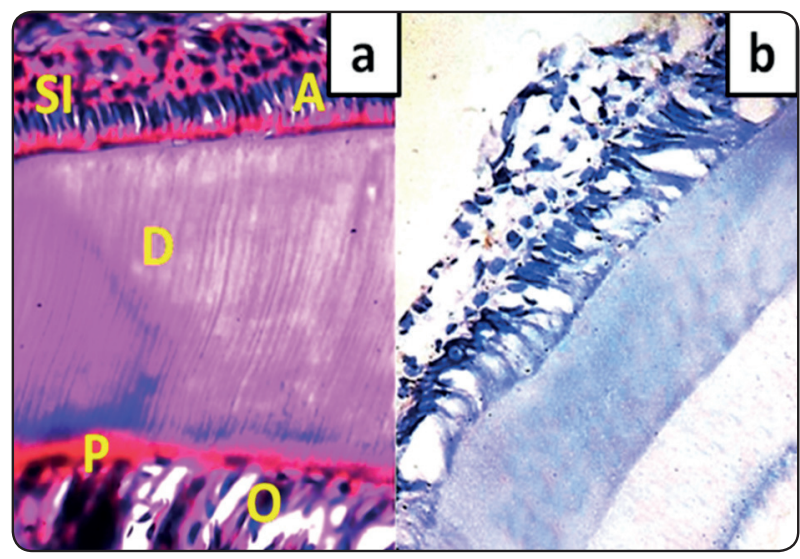

Fig. (11) Photomicrographs of the enamel organ at the late bell stage in 1 week aged mice showing: (a) Ameloblasts (A), stratum intermedium (SI), dentin (D), predentin (P) and odontoblasts (O) (H\&E X 400) (b) Negative TRAP immunostaining in all layers of the enamel organ (TRAP X 400) 


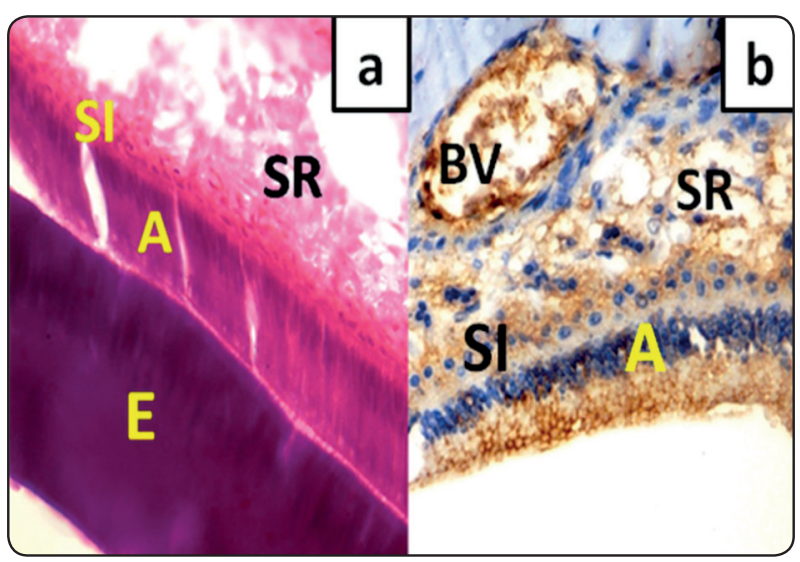

Fig. (12) Photomicrographs of the enamel organ at the late bell stage in adult mice showing: (a) Ameloblasts (A), stratum intermedium (SI), stellate reticulum (SR) and enamel matrix (E) (H\&E X 400) (b) Strongly positive reaction to TRAP immunostaining in Ameloblasts $(\mathrm{AM})$, stratum intermedium (SI), stellate reticulum (SR) and in the blood vessels adjacent to the outer enamel epithelium (BV) (TRAP X 400)

\section{DISCUSSION}

TRAP promotes the hydrolysis of a number of substrates, including nucleotides, aryl phosphates, and phosphoproteins (Hayman et al.,1989; Janckila et al., 1992 and Nash et al., 1993). Mice deficient in TRAP, generated by selective gene targeting, have demonstrated that TRAP is essential for the normal mineralization of cartilage in developing bones and for maintenance of the adult skeleton (Hayman et al., 1996). These knockout mice also displayed an impairment of macrophage function (Bune et al., 2001) with abnormal immunomodulatory cytokine response. In the mouse, TRAP was expressed in many tissues in addition to bone (Angel et al., 2000 and Hayman et al., 2000a, b), and the identification of the enzyme in murine dendritic cells suggests a function in T-cell immunity (Hayman et al., 2000a).

Accordingly, the current work was carried out to further investigate the normal distribution of TRAP among different mouse oral tissues at various ages. The mouse was the animal of choice in the present study since the human TRAP gene maps to chromosome $19 \mathrm{p}$, in a region syngenic to the mouse chromosome 9 (Lord et al., 1990), and males were selected due to the sexual dimorphism of the mouse submandibular salivary glands (Amano et al., 2012). Skin side of the lip, dorsal surface of the tongue and enamel organs were chosen in this investigation as these tissues have ectodermal origin and are not related to macrophage lineage. The submandibular salivary gland was preferred in this work as it undergoes functional differentiation in its structure after birth.

In the current investigation, histological examination of the submandibular salivary gland of 1day aged mice has revealed only serous acini and excretory ducts. Neither striated ducts nor granular convoluted tubules (GCTs) could be seen at this age. Similar observation was obtained by Gresik \& MacRae (1975), who found that striated ducts of mouse submandibular gland first appear at 5 days of age and reach their mature condition at about 20 days of age. While in human submandibular gland, Amano et al., (2012) reported that it is a mixed gland composed of both serous and mucous acinar cells; in rodent gland, only the serous type was found.

In 1 week aged mice, the submandibular salivary gland exhibited striated ducts but no evidence of GCTs. This coincides with the observations of Gresik \& Mac Rae, (1975) who demonstrated that GCTs, which differentiate from striated duct cells, are first seen at 15 days of age in both sexes, they show a more rapid development in males than in females, and are dimorphically represented by 20 days of age. The authors also added that the androgen-dependent differentiation of GCTs occurs at puberty. Furthermore, Jayasinghe et al., (1990) declared that the GCTs represent exocrine compartments in addition to the acini and they are fully developed at 4 weeks where they then comprise $19 \%$ of the gland volume in males, but only $8 \%$ in females. These observations support our findings in the adult male mice in which granular convoluted 
tubules were clearly seen in the submandibular gland.

Regarding the immunohistochemical expression of TRAP in submandibular glands of mice, negative expression occured in both one day and one week aged mice, while in adult mice TRAP immunoexpression was confined to the GCTs where a strong reaction was displayed. The principal cell type of the GCTs is a high-columnar secretory cell containing many apical secretory granules. These granules contain a variety of biologically active polypeptides such as cell growth factors and hormones that are exocytosed in response to neural and hormonal stimuli (Amano et al., 2012). These factors, including: epidermal growth factor (EGF), nerve growth factor (NGF) (Gresik, 1994 \& Gresik et al., 1996) and insulin-like growth factor- 1 (IGF-I) (Amano \& Iseki, 2001), could act directly on the mucosal membranes for their protection and repair. For example, EGF accelerates incisor eruption when injected into newborn rats or mice (Carpenter \& Cohen, 1979), inhibits acid secretion, protects gastric mucosa against injury, and accelerates mucosal ulcer healing by stimulating cell migration and proliferation (Tarnawski \& Jones, 1998).

In fact, saliva doesn't only contain digestive enzymes, but in particular the fraction secreted by the submandibular gland is enriched in mucosal glycoproteins, antimicrobial components, immunoglobulins, growth factors (including epidermal and nerve growth factors), and other regulatory substances such as small peptides and hormones (Barka, 1980). Many of these factors are packed in exosomes, small vesicles $(30-100$ $\mathrm{nm})$ generated by exocytosis of multivesicular endosomes (Thery et al., 2002) where type I transmembrane tartrate sensitive prostatic acid phosphatase (TMPAP) is present (Quintero et al., $2007 \&$ Quintero et al., 2013). In the present investigation, TRAP was strongly expressed in the granules of the GCTs, which may indicate its role in synthesizing and/or secreting growth factors by the cells of the GCTs.

In the present study, TRAP was expressed in the hair follicles and sebaceous glands of the skin side of the lip. This observation is similar to that of Hayman et al., (2001) who found that TRAP was present in the skin, with higher activity concentrated around the hair follicles than in the epidermis, and also that TRAP was expressed in the cells of stratum basale, in the regions of the developing papillae, and in a subepithelial layer to which Langerhans cells migrate. The presence of the enzyme in the skin and epithelial linings of the alimentary canal where it partially co-localizes with dendritic cells, immediately suggests an immune function and an early participation in the establishment of the accessory antigen presenting system for the developing immune responses (Hayman et al., 2000a). Recently, in vitro studies using recombinant TRAP have demonstrated that the rat enzyme is synthesised as a latent proenzyme with low activity which is activated by cysteine proteinases (Ljusberg et al., 1999).

Most tissues in the mouse embryos that expressed TRAP were also known to express cysteine proteinases (Qian et al., 1991 \& Szomor et al., 1995). It was thus proposed that, when required, TRAP may be locally activated by cysteine proteinases. Similarly, in bone resorption, lysosomal cysteine proteinases are actively synthesised and secreted by osteoclasts where they also may activate TRAP (Page et al., 1992 \& Drake et al., 1996). Several cysteine proteinases have also been identified in epidermal tissue, where they exist largely as inactive precursors which become activated in disease states such as skin cancers (Shamberger \& Rudolph, 1999). Taken together these observations suggest that the local activation of TRAP may be regulated by post-translational cleavage at these sites by cathepsins specifically expressed in antigen presenting cells. 
Hayman et al., (2001) reported the extent to which TRAP expression was localized to tissues and organs with environmentally exposed surfaces, including the skin, lung and gastrointestinal tract. Similarly, Janckila et al., (2007) detected TRAP immunoreactivity in the secretory epithelial cells of sebaceous glands and their connected hair root sheaths as well as in the macrophages of the lamina propria of human gastrointestinal tract (GIT), which may be another clue to the possible role of TRAP in innate resistance.

According to Ohno et al., (1989) who studied phosphoprotein phosphatase activity, which has biochemical properties corresponding to TRAP, in the rat's skin, they demonstrated that the enzyme was detected in granular cells and the lower strata of the cornified epidermis and was also localized in keratohyaline granules. These results could explain the expression of TRAP among the granular cell layer of the filiform papillae observed in the present investigation.

Regarding the immunohistochemical results of the enamel organ in the current work, TRAP was expressed in the ameloblasts, stratum intermedium, stellate reticulum and blood vessels adjacent to the outer enamel epithelium. On the contrary, Hayman et al., (2000b) demonstrated TRAP expression in the 18 day aged embryo in the superficial layers of enamel resorption by odontoclasts confirming the results of Sakakura et al., (1998) who observed a correlation between the formation of the dental follicle and the appearance of TRAP positive cells.

Conclusively, the observations of the present study have revealed the widely distributed immunolocalization of TRAP among various oral and dental tissues, other than those of macrophage lineages. And hence, TRAP expression was found not to be confined to osteoclasts. However, further investigations are still required to explore the underlying role of TRAP in processes other than bone resorption.

\section{CONCLUSION}

Using immunohistochemistry, we have identified the widespread expression of TRAP in some oral tissues of mice at different ages; these tissues included the submandibular salivary glands, skin side of the lip, dorsal surface of the tongue and various layers of the enamel organ. Besides, the expression of TRAP was intensely expressed in the tissues of adult mice rather than at earlier ages. These findings indicate that TRAP expression isn't restricted to osteoclasts, and thus, TRAP may be involved in biological processes other than bone remodeling.

\section{REFERENCES}

- Amano O. and Iseki S. (2001): Expression and localization of cell growth factors in the salivary gland: a review. Acta Anat Nippon. 71; 201-211.

- $\quad$ Amano O, Mizobe K, Bando Y and Sakiyama K (2012): Anatomy and Histology of Rodent and Human Major Salivary Glands ; Acta Histochem. Cytochem. 45 (5): 241-250.

- $\quad$ Angel NZ, Walsh N, Forwood MR, Ostrowski MC, Cassady AT, Hume DA (2000): Transgenic mice overexpressing tartrate-resistant acid phosphatase exhibit an increased rate of bone turnover. J Bone Miner Res 15:103-110.

- Barka T (1980): Biologically active polypeptides in submandibular glands. JHistochem Cytochem 8: 836-859.

- Bune AJ, Hayman AR, Evans MJ, et al. (2001): Mice lacking tartrateresistant acid phosphatase (Acp5) have disordered macrophage inflammatory responses and reduced clearance of the pathogen, Staphylococcus aureus. Immunology ;102:103-113.

- $\quad$ Burstone MS (1959): Histochemical demonstration of acid phosphatase activity in osteoclasts. J HistochemCytochem 7:39-41.

- Callis G, Sterchi D. (1998): Decalcification of Bone: Literature Review and Practical Study of Various Decalcifying Agents, Methods, and Their Effects on Bone Histology. The Journal of Histotechnology ;21;49-58.

- Carpenter G, Cohen S(1979): Epidermal growth factor. Annu Rev Biochem 48:193. 
- Drake FH, Dodds RA, James IE, Connor JR, Debouck C, Richardson S et al. (1996): Cathepsin K, but not cathepsins $\mathrm{B}, \mathrm{L}$ or $\mathrm{S}$, is abundantly expressed in human osteoclasts. Journal of Biological Chemistry 271, 12511-12516.

- $\quad$ Efstradiadis T and Moss DW (1985): Tartrate-resistant acid phosphatase as a marker of osteoclast function. Calci ${ }^{\circledR e d}$ Tissue International 34, 285 \pm 295 .

- Gresik E. W. and Mac Rae EK (1975): The postnatal development of the sexually dimorphic duct system and of amylase activity in the submandibular glands of mice. Cell and tissue research;157 (3) 411-422.

- Gresik E. W. (1994): The granular convoluted tubule (GCT) cell of rodent submandibular glands. Microsc. Res. Tech. 27; 1-24.

- $\quad$ Gresik E. W., Hosoi, K., Kurihara, K., Maruyama, S. and Ueha, T. (1996): The rodent granular convoluted tubule cell-an update. Eur. J. Morphol. 34; 221-224.

- Hayman AR, Warburton MJ, Pringle JAS, Coles B and Chambers TJ (1989): Purißcation and characterization of a tartrate-resistant acid phosphatase from human

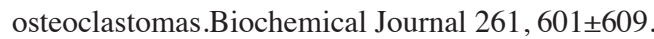

- Hayman AR, Jones SJ, Boyde A, Foster D, Colledge WH, Carlton MB et al. (1996): Mice lacking tartrate-resistant acid phosphatase (Acp 5) have disrupted endochondral ossifi- cation and mild osteopetrosis. Development 122, 3151-3162.

- Hayman AR, Bune AJ, Bradley JR, Rashbass J, Cox TM (2000a): Osteoclastic tartrate-resistant acid phosphatase (Acp 5): its localization to dendritic cells and diverse murine tissues. J Histochem Cytochem 48:219-228.

- Hayman AR, Bune AJ, Cox TM (2000b): Wide spread expression of tartrate-resistant acid phosphatase (Acp 5) in the mouse embryo. J Anat 196:433-441.

- Hayman AR, Macary P, Lehner P J and Cox TM (2001): Tartrate-resistant acid phosphatase (Acp 5): Identification in diverse human tissues and dendritic cells. J Histochem Cytochem 49(6): 675-683.

- Janckila AJ, Woodford TA, Lam K, Li C, Yam LT (1992): Protein-tyrosine phosphatase activity of hairy cell tartrateresistant acid phosphatase. Leukemia 6, 199-203.

- Janckila AJ, Yaziji H, Lear SC, Martin AW, Yam LT (1996): Localization of tartrate-resistant acid phosphatase in human placenta Histochem J 28:195-200.
- Janckila AJ, Slone SP, Lear SC, Martin A and Yam LT (2007): Tartrate-resistant acid phosphatase as an immunohistochemical marker for inflammatory macrophages. Am J Cli Pathol; 127:556-566.

- Jayasinghe NR, Cope GH, Jacob S (1990): Morphometric studies on the development and sexual dimorphism of the submandibular gland of the mouse. J Anat 172: 115-127.

- Ketcham CM, Roberts RM, Simmen RC, Nick HS (1989): Molecular cloning of the type 5, ironcontaining, tartrate-resistant acid phosphatase from human placenta. J BiolChem 264:557-563.

- $\quad$ Ljusberg J, Ek-Rylander B, Andersson G (1999): Tartrateresistant acid phosphatase is synthesised as a proenzyme and activated by cysteine proteinases. Biochemical Journal 343, 63-69.

- Lord DK, Cross NCP, Bevilacqua MA, Rider SH, Gorman PA, Groves AV et al. (1990): Type 5 acid phosphatase : sequence, expression and chromosomal localization of a differentiation-associated protein of the human macrophage. European Journal of Biochemistry 189, 287-293.

- Nash K, Feldmuller M, De Jersy J, Alewood P, Hamilton S (1993): Continuous and discontinuous assays for phosphotyrosyl protein phosphatase activity using phosphotyrosy peptide substrates. Analytical Biochemistry 213, 303-309.

- Ohno J, Fukuyama K, Hara A, Epstein WL (1989): Immuno- and enzyme-histochemical detection of phosphoprotein phosphatase in rat epidermis. J Histochem Cytochem 37:629-634.

- Page AE, Warburton MJ, Chamburs TJ, Pringle JAS, Hayman AR (1992): Human osteoclastomas contain multiple forms of cathepsin B. Biochimica Biophysica Acta 116, 57-66.

- Qian F, Chan SJ, Gong QM, Bajkowski AS, Steiner DF, Frankfater A (1991): The expression of cathepsin B and other lysosomal proteinases in normal tissues and in tumors. Biochimica et Biophysica Acta 50, 531-540.

- Quintero IB, Araujo CL, Pulkka AE, Wirkkala RS, Herrala AM, Eskelinen EL, Jokitalo E, Hellstrom PA, Tuominen HJ, Hirvikoski PP, Vihko PT (2007): Prostatic acid phosphatase is not a prostate specific target. Cancer Res 67: 6549-6554.

- Quintero IB, Herrala AM, Araujo CL, Pulkka AE, Hautaniemi S,Ovaska K, Pryazhnikov E, Kulesskiy E, 
Ruuth MK, Soini Y, Sormunen RT, Khirug L, Vihko PT (2013): Transmembrane prostatic acid phosphatase (TMPAP) interacts with snapin and deficient mice develop prostateadenocarcinoma. PLos One 8: e73072.

- Rico H, Villa LF. Serum tartrate resistant acid phosphatase (1993): (TRAP) as a biochemical marker of bone remodelling. Calcif Tissue Int;52:149-50.

- Robinson DB and Glew RH (1980): Acid phosphatase in Gaucher's disease. Clinical Chemistry 26, 371 2382 .

- Sahara N, Ashizawa Y, Nakamura K, Deguchi T, Suzuki K (1998): Ultrastructural features of odontoclasts that resorb enamel in human deciduous teeth prior to shedding. Anat Rec 252:215-228.

- $\quad$ Sakakura Y, Yajima T, Tsuruga E (1998): Confocal laser scanning and microscopic study of tartrate-resistant acid phosphatase-positive cells in the dental follicle during early morphogenesis of mouse embryonic molar teeth. Archives of Oral Biology 43, 353-360.

- Shamberger RJ, Rudolph G (1999): Increase of lysosomal enzymes in skin cancers. Nature 213, 617-618.

- Szomor Z, Shimizo K, Fugimori Y, Yamamoto S, Yamamuro T (1995): Appearance of calpain correlates with arthritis and cartilage destruction in collagen induced arthritic knee joints of mice. Annals of Rheumatic Disorders 54, 477-483.

- Tarnawski, A. S. and Jones, M. K. (1998): The role of epidermal growth factor (EGF) and its receptor in mucosal protection, adaptation to injury, and ulcer healing: involvement of EGF-R signal transduction pathways. J. Clin. Gastroenterol. 27 Suppl 1; S12-20.

- Thery C, Zitvogel L, Amigorena S (2002): Exosomes: composition, biogenesis and function. Nat Rev Immunol 2: $569-579$. 